Check for updates

Cite this: RSC Adv., 2017, 7, 34875

\title{
Nanomaterials for photocatalytic hydrogen production: from theoretical perspectives
}

\author{
Mahesh Datt Bhatt (iD and Jae Sung Lee (iD *
}

To overcome the increasing demand of energy worldwide and global warming due to $\mathrm{CO}_{2}$ emissions from the use of traditional fuel sources, renewable and clean energy sources are in high demand. Solar energy is one of the important renewable energy sources since it can be converted into hydrogen fuel via water splitting. To produce highly efficient and low-cost $\mathrm{H}_{2}$ from the reduction of water and $\mathrm{CO}_{2}$, photocatalytic materials have been developed. Presently, the efficiency of $\mathrm{H}_{2}$ production using transition metal-oxide and non-metal oxide photocatalysts via water splitting is quite low. The main issues reported are low light absorption and poor charge separation. The reasons for these two issues are the large band gaps and band edge positions of the present photocatalysts used for $\mathrm{H}_{2}$ production. To produce $\mathrm{H}_{2}$ to a larger extent from the decomposition of water, the present photocatalysts have been modified by co-catalysts or dopants using different techniques, including the reduction of the band gap and adjustment of the morphology, band edge positions, crystallinity, surface structure, etc., such that these photocatalysts can absorb sufficient light in the visible-light region. This type of modified nanostructured photocatalysts (both oxide and non-oxide) can enhance the efficiency of $\mathrm{H}_{2}$ production via absorbing sufficient light in the visible-light region of the solar spectrum and improving the charge separation by suppressing charge recombination. In this regard, we reviewed both UV- and visible-light active nanostructured photocatalysts and modified photocatalysts reported in theoretical studies.

Received 24th March 2017 Accepted 6th June 2017

DOI: $10.1039 / c 7 r a 03435 k$

rsc.li/rsc-advances

\section{Introduction}

The use of traditional energy sources, such as fossil and mineral fuels and nuclear and hydroelectric sources, causes global warming due to the emission of $\mathrm{CO}_{2}$, methane, $\mathrm{CO}$, etc. that can cause serious disasters in various places worldwide. Moreover, there is a continuous depletion of traditional energy sources. To solve these issues, alternative energy sources, such as renewable energy sources, have been developed by researchers worldwide to meet the world's energy needs as well as to decrease pollution.

Various types of renewable energy sources are under development or have been developed. Among these, hydrogen can be a promising potential candidate and its production from renewable energy sources is $\mathrm{CO}_{2}$-free. In this regard, hydrogen can be considered as a clean energy carrier that can address the current energy and environmental issues. ${ }^{1,2}$

Hydrogen can be produced from primary energy sources including coal, natural gas, waste, biomass, solar, wind, hydropower, nuclear power, and geothermal power. For example, commercial hydrogen can be produced via steam reforming of methane ${ }^{3,4}$ and also from coal using gasification

School of Energy \& Chemical Engineering, Ulsan National Institute of Science \& Technology (UNIST), Ulsan, 689-798, Republic of Korea. E-mail: jlee1234@unist.ac.kr technology; however, both these methods result in $\mathrm{CO}_{2}$ emissions. Hydrogen can be stored in its gaseous, liquid, or metal hydride form and can be distributed over large distances via pipelines or tankers. Numerous studies have been carried out to discuss the key role of hydrogen in sustainable development. ${ }^{5-10}$

The abundant supply of water and sunlight offers us an affordable alternative source to produce hydrogen. Therefore, photocatalytic water splitting is one of the potential techniques for clean solar hydrogen production and has been utilized in small- to large-scale hydrogen generators. ${ }^{11}$ In 1972, Honda and Fujishima ${ }^{12}$ first investigated water splitting using a single $\mathrm{TiO}_{2}$ crystal as a photoanode and Pt as a cathode. Subsequently, numerous studies on water splitting have been conducted ${ }^{13-19}$ with the exploration of more than 100 different new catalysts including multi-component oxides, sulfides, nitrides, and carbides. All of them are concentrated on the various factors affecting the conversion efficiency such as how much sunlight is absorbed, the exciton generation, the separation/recombination of holes and electrons received by dissociation of excitons, and the charge collection by the respective electrodes to produce hydrogen and oxygen. Some other practical factors are also important for photocatalytic hydrogen production such as stability and resistance under visible light, reduced cost, and non-toxicity of utilized materials. ${ }^{20-23}$ In this regard, we speculated that photocatalytic hydrogen could be a commercial fuel 
in future; however, significant research efforts should be devoted in this direction, addressing the abovementioned key issues for its industrial production.

Nanomaterials such as CdS, SiC, $\mathrm{CuInSe}$, and $\mathrm{TiO}_{2}$ can be utilized to produce cheap and clean photocatalytic hydrogen ${ }^{24-27}$ due to the fact that these nanomaterials show better photocatalytic properties as compared to their bulk counterparts. Currently, many other nanomaterials such as $\mathrm{Nb}_{2} \mathrm{O}_{5},{ }^{28} \mathrm{Ta}_{2} \mathrm{O}_{5},{ }^{29}$ $\alpha-\mathrm{Fe}_{2} \mathrm{O}_{3},{ }^{30,31} \mathrm{ZnO},{ }^{32,33} \mathrm{TaON},{ }^{34} \mathrm{BiVO}_{4},{ }^{35,36}$ and $\mathrm{WO}_{3}$ have been explored. ${ }^{37}$ In most of the photocatalysts, band gap limitation is a key issue that results in low $\mathrm{H}_{2}$ production. ${ }^{38}$ To solve this issue, some photocatalysts have been modified via noble metal doping, ion doping, sensitization, and metal-ion implantation. In noble metal doping, Pt has been found to be the best noble metal; however, it is too expensive. Thus, other efficient and cheaper metals such as $\mathrm{Ni}, \mathrm{Cu}, \mathrm{Ag}, \mathrm{Ru}, \mathrm{Pd}$, and Ir have been explored. ${ }^{39-47}$ Ion doping involves transition metal and rareearth metal ions, anions of nitrogen and sulphur, etc. Sensitization means dye-sensitization and coupling of semiconductors. Among the abovementioned modification techniques, metal-ion implantation and dye-sensitization have been found to be the most effective photoanode surface modification techniques. Moreover, researchers are interested in exploring co-catalysts with photocatalyst nanomaterials that can be used for photocatalytic hydrogen production.

The theoretical and computational description of many body systems is still one of the biggest challenges in solid state science although significant progress has been made in this regard. The majority of theoretical and computational studies on photocatalytic nanomaterials have used density functional theory (DFT) because DFT predicts the ground-state properties in terms of electronic density. The band gap of the materials is often significantly underestimated by DFT, ${ }^{48}$ computed using Kohn-Sham method by introducing an exchange correlation (XC) functional such as local density approximation (LDA) ${ }^{49}$ or the generalized gradient approximation (GGA). ${ }^{\mathbf{5 0}}$ The band gap of the materials can be improved by applying several approaches. For example, a hybrid functional can improve the accuracy by combining the approximate DFT functionals (LDA or GGA) with the exact Hartree-Fock (HF) exchange energy. ${ }^{51}$ Alternatively, the DFT $+\mathrm{U}$ method with the Hubbard band $\mathrm{U}$ term can provide more accurate results. ${ }^{52}$ The accuracy of these two approaches depends on the selection of several empirical parameters. Moreover, the parameter-free GW method yields an accurate description of the electronic structure of the materials, but at a huge computational expense. ${ }^{53}$ Therefore, the use of GW method is not more reliable for complex structures.

Herein, the study was concentrated on modeling a nanostructured photocatalyst and modified nanophotocatalysts at the atomic level to provide information on the key atomic level structures, processes, and parameters that control the behavior of photocatalytic materials during their applications in photocatalytic $\mathrm{H}_{2}$ production. In particular, substantial contributions have been made by modeling methods in the study of the electronic states, defects, and surface properties of nanophotocatalysts for $\mathrm{H}_{2}$ production.

\section{Theoretical achievements for the development of nanophotocatalysts and modified photocatalysts for hydrogen production via water splitting}

Many nanophotocatalysts have been developed to split water into $\mathrm{H}_{2}$ and $\mathrm{O}_{2}$ under UV and visible-light illumination. The industrial production of clean and recyclable $\mathrm{H}_{2}$ via the direct splitting of water using a particulate photocatalyst could be the best method.$^{54-57}$ However, there is a lack of suitable materials with appropriate band gap positions for overall water splitting, and stability is required for practical applications. The reason is that most metal oxides have optical band gaps that lie outside the visible-light range $\left(E_{\mathrm{g}}>3 \mathrm{eV}\right)$; thus, even if they are catalytically active for a given reaction, they cannot make efficient use of the solar spectrum. For example, $\mathrm{TiO}_{2}$ has a wide band gap $\left(E_{\mathrm{g}}=3.2 \mathrm{eV}\right)$, which is limited to a $1 \%$ solar-to-hydrogen (STH) conversion efficiency for the water splitting process, whereas for a smaller band gap material such as $\mathrm{Fe}_{2} \mathrm{O}_{3}\left(E_{\mathrm{g}}=2.2\right.$ $\mathrm{eV}$ ), the theoretical efficiency increased to $15 \% .^{58}$ The STH of $10 \%$ is required for the solar cell-powered electrolysis of water. Therefore, the development of highly active photocatalysts should be explored for large-scale photocatalytic $\mathrm{H}_{2}$ production via water splitting. ${ }^{59-62}$ There are two types of nanostructured photocatalyst materials for $\mathrm{H}_{2}$ production via water splitting.

\section{(i) Metal-oxide photocatalysts and modified metal-oxide photocatalysts (with hybrid systems)}

Although there have been many experimental investigations reported on metal oxide nanophotocatalysts for $\mathrm{H}_{2}$ production via water splitting under UV- and visible-light irradiation, very few theoretical investigations based on the DFT methods have been reported. Among these, most theoretical investigations have been reported on nanostructured $\mathrm{TiO}_{2}$ and modified $\mathrm{TiO}_{2}$ photocatalysts. For example, Kaur et $a l .{ }^{63}$ investigated amorphous $\mathrm{TiO}_{2}$ as a photocatalyst for $\mathrm{H}_{2}$ production using the DFT methods. The authors claimed via the analysis of the electronic properties that amorphous $\mathrm{TiO}_{2}$ may act as a cheaper, more abundant, but somewhat less efficient photocatalyst as compared to crystalline $\mathrm{TiO}_{2}$. To improve the photocatalytic activity of the $\mathrm{TiO}_{2}$ nanophotocatalyst, the doping of $\mathrm{TiO}_{2}$ was carried out using different techniques via narrowing the band gap of $\mathrm{TiO}_{2}$ to absorb more visible-light in the solar spectrum as well the dependence of charge separation and recombination on the distance between the catalytic core and semiconductor surface. For example, Reynal et al. ${ }^{64}$ reported that the photoinduced reduction of $\mathrm{H}_{2}$ on a Co electrocatalyst immobilized on $\mathrm{TiO}_{2}$ was $10^{4}$ times faster than the reverse charge recombination. The authors claimed that both processes show an exponential dependence on the distance between the semiconductor and the catalytic core, as shown in Fig. 1(a)-(d). ${ }^{64}$ As shown in Fig. 1, the authors computed the charge separation and recombination processes when a semiconductor $\left(\mathrm{TiO}_{2}\right)$ was functionalized with three related cobalt electrocatalysts, whose 

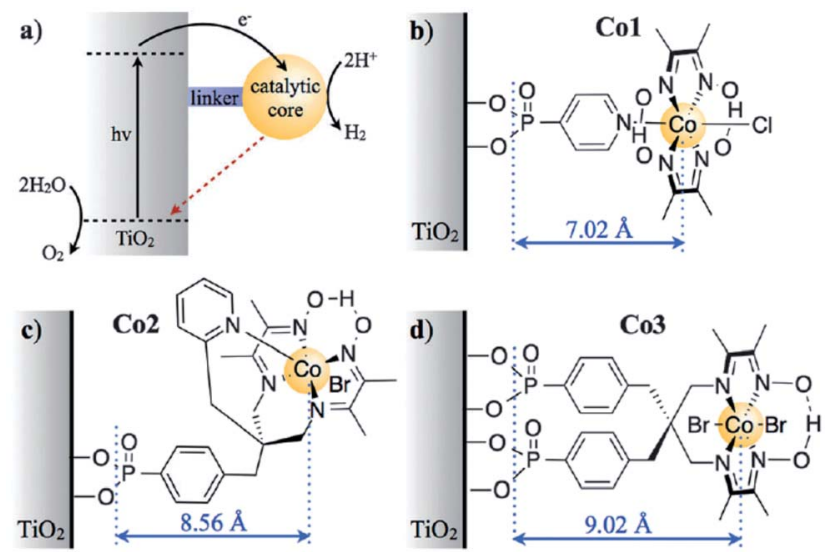

Fig. 1 (a) The electron transfer processes in $\mathrm{TiO}_{2}$ functionalised with a molecular catalyst for $\mathrm{H}_{2}$ production after UV-light excitation. The solid black and dashed red arrows indicate the charge separation and recombination, respectively. The molecular structures of the catalysts for $\mathrm{H}_{2}$ reduction are shown in (b) for $\mathrm{Co}$, (c) for $\mathrm{Co}$, and (d) for $\mathrm{Co} 3$ (the charges have been omitted for clarity). The blue arrows indicate the distance between the anchoring groups and the catalyst metal centre $(r, A)$, as determined by the energy minimised DFT calculations. Reprinted with permission of ref. 64. Copyright 2014 Royal Society of Chemistry.

molecular structure varied the physical separation between the catalytic core and the semiconductor surface. In this hybrid system, the semiconductor acted as a light harvester and $\mathrm{H}_{2}$ evolution was driven by the anchored molecular catalyst. Some theoretical investigations have shown that $\mathrm{BaTiO}_{3}$ (ref. 65 and 66) and $\mathrm{PbTiO}_{3}$ (ref. 67-69) nanowires exhibit ferroelectricity and $\mathrm{Bi}_{2} \mathrm{Ti}_{2} \mathrm{O}_{7},{ }^{70} \mathrm{SrTiO}_{3},{ }^{71}$ and $\mathrm{CaTiO}_{3}$ (ref. 72) nanowires exhibit photocatalytic activity towards water splitting. Bandura et al. ${ }^{73}$ demonstrated the photocatalytic activity of $\mathrm{SrTiO}_{3}$ nanowires and concluded that via comparison of the band edge positions and Fermi levels relative to the levels of the reduction $\mathrm{H}^{+} / \mathrm{H}_{2}$ and oxidation $\mathrm{O}_{2} / \mathrm{H}_{2} \mathrm{O}$ potentials as well as analysis of the band gap widths, the probable $\mathrm{SrTiO}_{3}$ nanowire configurations and $\mathrm{SrTiO}_{3}$ nanotube ${ }^{74}$ configurations can be suggested for application in the photocatalytic splitting of water molecules under solar irradiation in the visible-light range.

In the case of $\mathrm{TiO}_{2}$, the phase of the photocatalyst is a key factor for its photocatalytic activity. For example, although the rutile phase exhibits a narrower band gap (approx. $3.0 \mathrm{eV}$ ) than the anatase phase (approx. $3.2 \mathrm{eV}$ ), ${ }^{7-77}$ anatase is generally considered to exhibit superior photocatalytic activity due to its larger surface area and thus higher activity. ${ }^{78}$ The third metastable phase is brookite that has also been reported to exhibit photocatalytic activity, ${ }^{79,80}$ and mixtures of anatase, rutile, and brookite have been reported to exhibit significant photocatalytic activity. ${ }^{81,82}$ However, this phase is of lesser interest due to the complexity of its synthesis. The doping of $\mathrm{TiO}_{2}$ can provide several outcomes: formation of new valence states in $\mathrm{TiO}_{2},{ }^{83-86}$ creation of charge carrier trapping sites ${ }^{87-90}$ band gap reduction, ${ }^{91-93}$ control of phase transformation behavior, ${ }^{94-97}$ and surface enhancement. ${ }^{96,98}$ The effects of dopants on the anatase to rutile phase transformation have been comprehensively reviewed elsewhere. ${ }^{99}$ The phase transformation mainly occurs due to the atomic rearrangement involved in the transformation, which is often a result of an increase in the density of the anion vacancies. This may occur when cationic dopants of low valence substitute $\mathrm{Ti}$ in the anatase lattice. ${ }^{79,99,100}$ Hanaor et al. ${ }^{100}$ performed DFT calculations for the relative stability of anatase and rutile polymorphs of $\mathrm{TiO}_{2}$. The rutile phase exhibited a stability of $3 \mathrm{meV}$ as compared to the anatase phase in pristine $\mathrm{TiO}_{2}$. The authors also demonstrated the doping of $\mathrm{TiO}_{2}$ with $\mathrm{Si}, \mathrm{Al}, \mathrm{Fe}$, and $\mathrm{F}$ atoms and found that the anatase phase stabilized the rutile phase in the dopant order $\mathrm{F}>\mathrm{Si}>\mathrm{Fe}>$ Al obtained via comparison of $\Delta F\left(\mathrm{a}^{-} \mathrm{TiO}_{2}: \mathrm{F}\right)$ with $\Delta F\left(\mathrm{r}-\mathrm{TiO}_{2}: \mathrm{F}\right)$, which provided their formation energies as $84.78,32.43,18.46$, and $17.68 \mathrm{meV}$, respectively. As the authors considered only flourine anion dopant in their study, the inhibition of rutile formation via $\mathrm{F}$ doping was supported by previously reported experimental results. ${ }^{101,102} \mathrm{~A}$ schematic of the interstitial and substitutional dopant positions in anatase and rutile $\mathrm{TiO}_{2}$ is shown in Fig. 2(a) and (b). ${ }^{100}$

In general, efforts to modify $\mathrm{TiO}_{2}$ to enhance the visible-light absorption have been focused on the substitution of metal cations and/or non-metal anions. ${ }^{103-111}$ In some cases, the choice of DFT methodology can have an influence on the reduction of the band gap to the visible-light region of the solar spectrum. ${ }^{109}$ Co-doping with compensating cation-anion pairs from DFT simulations has been reported, ${ }^{112,113}$ along with a recent experimental study of Mo-C co-doped $\mathrm{TiO}_{2} \cdot{ }^{114} \mathrm{Key}$ parameters such as stability, solubility, and reproducibility are also important along with the band gap reduction as well as the method of doping and/or the DFT methodology to enhance the photocatalytic activity of $\mathrm{TiO}_{2}$ due to minimum charge recombination. Moreover, nanostructure engineering of $\mathrm{TiO}_{2}$ can reduce the charge recombination. ${ }^{115-119}$ In this regard, heterostructure techniques of $\mathrm{TiO}_{2}$ with other oxides can enhance the photocatalytic activity to tune the structure to increase the absorption of visible-light. ${ }^{120-133}$ For example, heterostructures such as $\mathrm{Bi}_{4} \mathrm{Ti}_{3} \mathrm{O}_{12}-\mathrm{TiO}_{2},{ }^{124} \mathrm{MgO}-\mathrm{TiO}_{2},{ }^{134}$ and $\mathrm{Ga}_{2} \mathrm{O}_{3}-\mathrm{TiO}_{2}$ (ref. 134) can reduce the band gap, leading to visible-light photoactivity, efficient charge separation, and improved photocatalytic activity as compared to pure $\mathrm{TiO}_{2}$.

In the case of the $\mathrm{Bi}_{4} \mathrm{Ti}_{3} \mathrm{O}_{12}-\mathrm{TiO}_{2}$ heterostructure, $\mathrm{Bi} 6 \mathrm{~s}$ mainly contributes to the valence band, whereas the Bi $6 \mathrm{p}$ state contributes to the conduction band, which result in the reduction of the band gap of $\mathrm{Bi}_{4} \mathrm{Ti}_{3} \mathrm{O}_{12}(2.5 \mathrm{eV})$ as compared to that of $\mathrm{TiO}_{2}(3.2 \mathrm{eV})$. This leads to large absorption of visible-

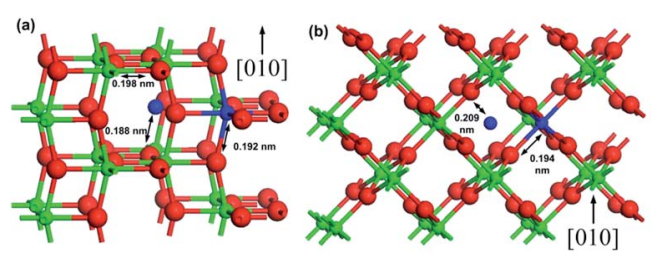

Fig. 2 A schematic of the interstitial and substitutional dopant positions in (a) anatase and (b) rutile $\mathrm{TiO}_{2}$ with the arrows showing the cation-dopant to oxygen distances. Reprinted with permission of ref. 100. Copyright 2012 Springer-Verlag Berlin Heidelberg. 
light. A schematic showing the energy band structure and electron-hole pair separation in the $\mathrm{Bi}_{4} \mathrm{Ti}_{3} \mathrm{O}_{12}-\mathrm{TiO}_{2}$ heterostructure is shown in Fig. $3 .^{\mathbf{1 2 4}}$ Similarly, in the case of $\mathrm{MgO}-$ $\mathrm{TiO}_{2}$ and $\mathrm{Ga}_{2} \mathrm{O}_{3}-\mathrm{TiO}_{2}$ heterostuctures, the author claimed the presence of two states in the band gap, as shown in Fig. $4 .^{134}$ The first state comes from an occupied $\mathrm{Ti}^{3+}$ state at $0.9 \mathrm{eV}$ and $1.0 \mathrm{eV}$ above the valence band edge in the $\mathrm{MgO}-\mathrm{TiO}_{2}$ and $\mathrm{Ga}_{2} \mathrm{O}_{3}-\mathrm{TiO}_{2}$ heterostuctures, respectively. The second state comes from an unoccupied $\mathrm{O} 2 \mathrm{p}$ state (oxygen hole polaron), which lies $1.8 \mathrm{eV}$ and $1.5 \mathrm{eV}$ above the valence band of the $\mathrm{MgO}-\mathrm{TiO}_{2}$ and $\mathrm{Ga}_{2} \mathrm{O}_{3}-$ $\mathrm{TiO}_{2}$ heterostuctures, respectively. These results show that the excitonic electrons and holes are localized on the $\mathrm{TiO}_{2}$ and the metal oxide nanostructures, which lead to a reduction in charge recombination and an enhancement in the photocatalytic activity.

In addition, $\mathrm{TiO}_{2}$ nanoparticles can attach materials such as zeolites, ${ }^{135}$ silica, ${ }^{136}$ activated carbon ${ }^{137-142}$ or carbon nanotubes. ${ }^{\text {143-149 }}$ Recently, graphene has attracted significant interest ${ }^{\mathbf{1 5 0 - 1 5 4}}$ due to its large surface area and potentially higher photocatalytic efficiency. ${ }^{155}$ However, very few reports are available for theoretical investigations on the interaction of nanoparticles and graphene sheets, and the mechanism of charge transfer from graphene to the nanoparticles. The decorated surface of graphene with both $\mathrm{TiO}_{2}$ nanofibers ${ }^{\mathbf{1 5 5}}$ and $\mathrm{Fe}$ doped $\mathrm{TiO}_{2}$ nanofibers ${ }^{\mathbf{1 5 6}}$ in supercritical carbon dioxide exhibits high photocatalytic activity. Das et $a .^{157}$ deposited different semiconductor nanoparticles, such as $\mathrm{TiO}_{2}$ and $\mathrm{ZnO}$, and some magnetic nanoparticles, such as $\mathrm{Fe}_{3} \mathrm{O}_{4}$ and $\mathrm{Ni}$, on graphene. They calculated their electronic structure using DFT methods and found that charge transfer occurred between graphene and the deposited nanoparticles.

Among all the metal oxides, $\mathrm{WO}_{3}$ has attracted significant interest due to its photosensitivity, ${ }^{\mathbf{1 5 8 - 1 6 0}}$ good electron transport properties, ${ }^{161}$ and stability against photocorrosion. ${ }^{162,163}$ Moreover, its smaller band gap (approx. $2.8 \mathrm{eV}$ ) than other oxides such as $\mathrm{TiO}_{2}$ makes it suitable for the absorption of visible-light. However, the gap of $\mathrm{WO}_{3}$ is still too large for sufficient visiblelight absorption. Experimental results have shown that the conduction band minimum (CBM) of bulk $\mathrm{WO}_{3}$ is about $0.4 \mathrm{eV}$ below the hydrogen redox potential. ${ }^{\mathbf{1 6 4 , 1 6 5}}$ For the $\mathrm{WO}_{3}$ surface, the CBM lies $0.31 \mathrm{eV}$ above the hydrogen redox potential, which is still low for hydrogen production. ${ }^{\mathbf{1 6 6}}$

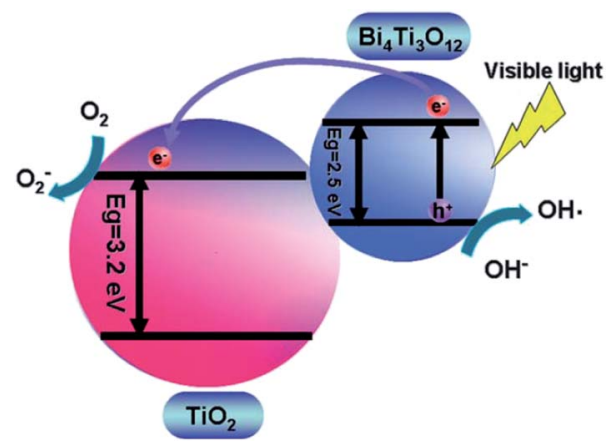

Fig. 3 A schematic showing the energy band structure and electronhole pair separation in the $\mathrm{Bi}_{4} \mathrm{Ti}_{3} \mathrm{O}_{12} / \mathrm{TiO}_{2}$ heterostructure. Reprinted with permission of ref. 124. Copyright 2011 Royal Society of Chemistry.
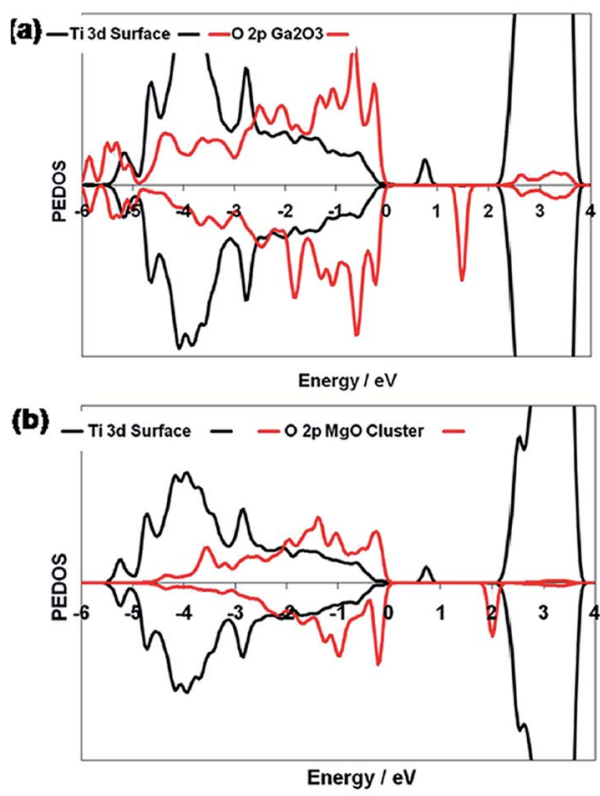

Fig. 4 Ti $3 d$ and $O 2 p$ PEDOS of the $\left(\mathrm{Ga}_{2} \mathrm{O}_{3}\right)_{2}$ and $(\mathrm{MgO})_{4}$ clusters for the relaxed triplet excited states of (a) $\mathrm{Ga}_{2} \mathrm{O}_{3}$-modified $\mathrm{TiO}_{2}$ and (b) $\mathrm{MgO}$-modified $\mathrm{TiO}_{2}$. The zero of energy is the top of the valence band. Reprinted with permission of ref. 134. Copyright 2012 American Chemical Society.

Doping and co-doping are good ways to tailor the electronic structure and photocatalytic properties of semiconducting oxides. For example, Mo-doped $\mathrm{WO}_{3}$ nanowires showed an enhancement in visible-light photoactivity, as the band gap of the $\mathrm{Mo}_{x} \mathrm{~W}_{1-x} \mathrm{O}_{3}$ solid solutions was narrowed by $0.48 \mathrm{eV}$ upon increasing the Mo content from 0 to $0.75 .{ }^{167,168}$ The effect of several transition metals on the photocatalytic activity under UV irradiation was also studied, suggesting maximum $\mathrm{H}_{2}$ production via Ni doping with $\mathrm{WO}_{3}{ }^{169}$ Doping with other metals (Ti, $\mathrm{Zn}$, Dy, Te, Ta, V, Cu, Ag, and Ce) has also been reported in the literature, ${ }^{\mathbf{1 7 0 - 1 7 8}}$ with some claims of improved photocatalytic activity. For example, Wang et al. ${ }^{179}$ studied $\mathrm{Mo}, \mathrm{Cr}, \mathrm{Ti}, \mathrm{Zr}$, and Hf-doped $\mathrm{WO}_{3}$ and found that in Hf-doped $\mathrm{WO}_{3}$, the oxygen vacancies have a negative formation energy, which leads to a shift in both the VB and CB to higher energies and a reduction of the band gap, with potential benefits for photocatalytic $\mathrm{H}_{2}$ production, as shown in Fig. $5 .^{\mathbf{1 7 9}}$

In previous studies, it has been reported that perovskite-type alkali tantalates, $\mathrm{ATiO}_{3}(\mathrm{~A}=\mathrm{Li}, \mathrm{Na}$, and $\mathrm{K})$ show significant photocatalytic activity under UV irradiation. However, these are less active under visible-light irradiation. ${ }^{\mathbf{1 8 0 , 1 8 1}}$ Transition metal ions were found to be attractive dopants for the effective modification of photocatalysts, which can play multiple roles ranging from reducing the band gap to efficient electron transfer due to their multiple oxidation states. ${ }^{\mathbf{1 8 2 , 1 8 3}}$ Electron transitions from the valence band to the dopant level or from the dopant level to the conduction band can effectively red shift the band edge absorption threshold.

For example, Liu et al. ${ }^{\mathbf{1 8 4}}$ demonstrated M-doped $\mathrm{NaTaO}_{3}$ $(\mathrm{M}=\mathrm{V}, \mathrm{Cr}, \mathrm{Mn}, \mathrm{Fe}, \mathrm{Ni}, \mathrm{Cu}$, and $\mathrm{Zn}$ ) nanoparticles using both experimental and DFT techniques. The authors found that the 


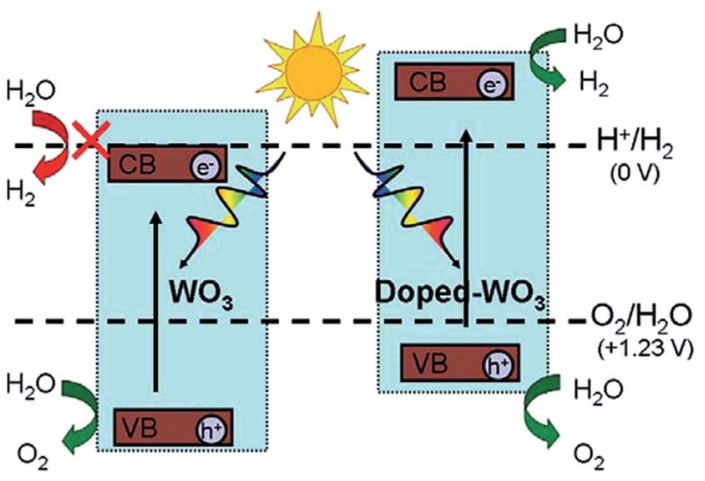

Fig. 5 A schematic of the superior photocatalytic activity of metaldoped $\mathrm{WO}_{3}$ for $\mathrm{H}_{2}$ production as compared to that of $\mathrm{WO}_{3}$. Reprinted with permission of ref. 179. Copyright 2012 American Chemical Society.

substitution of $\mathrm{Ta}^{3+}$ by metal ions results in the formation of an intermediate band, which is due to the metal $3 \mathrm{~d}$ state. The supercell of M-doped $\mathrm{NaTaO}_{3}$, total and projected DOS of pure and V-doped $\mathrm{NaTaO}_{3}$, and intermediate band formation by the d-orbitals of the doping metal ions are shown in Fig. 6(a), (b) and (c), respectively. ${ }^{184}$

Moreover, a $\mathrm{ZnO} /$ graphene hybrid nanostructure was reported to have excellent potential for application in electronic devices. ${ }^{\mathbf{1 8 5 - 1 9 0}}$ Most studies on the $\mathrm{ZnO} /$ graphene hybrid structures have been focused on their structural morphology and electronic properties. ${ }^{191,192}$ Recently, Xiang et $a l .{ }^{193}$ first proposed a three-component composite, $\mathrm{TiO}_{2} /$ graphene/ $\mathrm{MoS}_{2}$, containing $0.25 \mathrm{wt} \%$ graphene. The results showed that graphene acts as an electron reservoir and $\mathrm{MoS}_{2}$ can act as a source of active adsorption sites to achieve a highly efficient synergetic $\mathrm{H}_{2}$ evolution at the rate of $165.3 \mu \mathrm{mol} \mathrm{h}{ }^{-1}$, which is 17 times that of $\mathrm{TiO}_{2} / \mathrm{MoS}_{2} \cdot{ }^{194} \mathrm{Wu}$ et al. ${ }^{195}$ studied $\mathrm{ZnO}$-dotted porous $\mathrm{ZnS}$ cluster microspheres for highly efficient, Pt-free photocatalytic $\mathrm{H}_{2}$ evolution.

\section{(ii) Non-metal oxide photocatalysts and modified non-metal oxide photocatalysts (with hybrid systems)}

The surface modification of oxide photocatalysts, particularly $\mathrm{TiO}_{2}$, via doping with $\mathrm{N}, \mathrm{C}$ or $\mathrm{S}$, or metal nanoparticles cannot provide significant photocatalytic activity in the modified

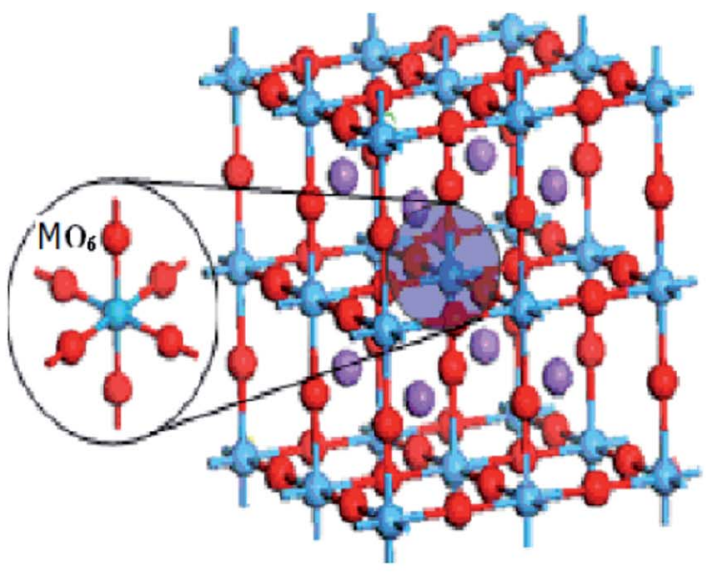

(a)

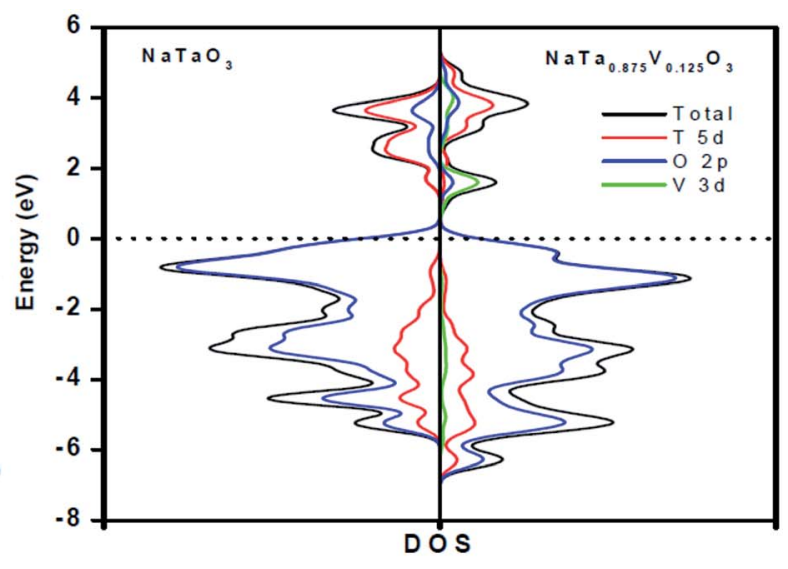

(b)

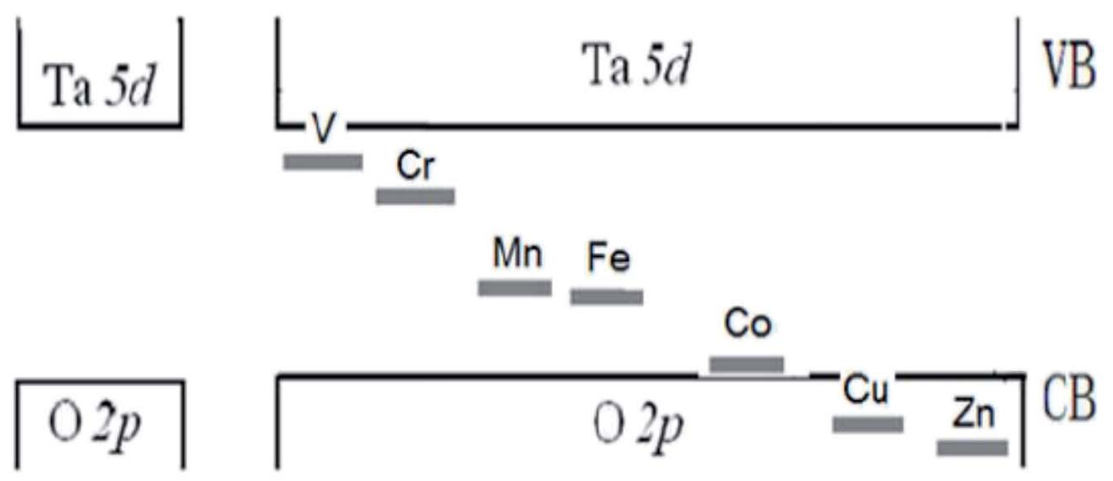

$\mathrm{NaTaO} 3$

\section{M-dop $\mathrm{NaTaO} 3$}

\section{(c)}

Fig. 6 (a) A supercell of $\mathrm{M}$-doped $\mathrm{NaTaO}_{3} 2 \times 2 \times 2$ (40-atoms), (b) the total density of states and projected density of states of the pure and $\mathrm{V}$ doped $\mathrm{NaTaO}_{3}$, and (c) intermediate band formation by the d-orbital of the doped metal ions. Reprinted with permission of ref. 184. Copyright 2012 IACSIT Press, Singapore. 
materials in the visible-light region of the solar spectrum. ${ }^{\mathbf{1 9 6 , 1 9 7}}$ Therefore, researchers have been interested in exploring alternative materials for nanophotocatalysts and modified photocatalysts for photocatalysis and solar energy conversion. As a result, the large-scale production of stable visible-light active photocatalysts remains a challenge for industrial applications. ${ }^{198}$ For example, polymeric carbon nitride has been found to be an efficient photocatalyst that produces $\mathrm{H}_{2}$ from water under visible-light irradiation; however, in this case, a sacrificial donor is required. ${ }^{199}$ Similarly, a class of metal-free photocatalysts, including elemental boron, ${ }^{200}$ sulfur, ${ }^{201}$ and phosphor, ${ }^{202}$ as well as the binary carbon nitride ${ }^{203}$ and boron carbide, has emerged. ${ }^{204}$ Conjugated polymer nanostructures have emerged as alternate materials for applications in solar energy conversion. However, there is a lack of photocatalytic studies of these conjugated polymers. Semiconductor nanostructures modified with conducting polymers have been studied for photocatalytic applications. Two-dimensional materials such as graphene ${ }^{\mathbf{2 0 5}}$ and layered hexagonal (h-BN) are promising photocatalysts. ${ }^{206-208}$ However, graphene (monolayer) exhibits a zero band gap, whereas h-BN exhibits a wide band gap $(\sim 5.5 \mathrm{eV})$. These materials (say ternary $\mathrm{B}-\mathrm{C}-\mathrm{N}$ compounds) can constitute the desired medium band gap semiconductors via adjustment of the band gap and absolute energy levels via chemical variations. ${ }^{209,210}$ Similarly, graphene oxide based on a carbon support may improve the charge separation and spontaneous redox processes. ${ }^{211,212}$ In recent years, graphene-based heterogenous photocatalytic

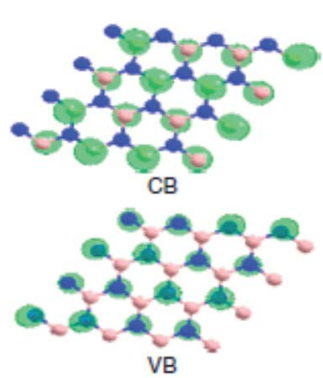

(a)

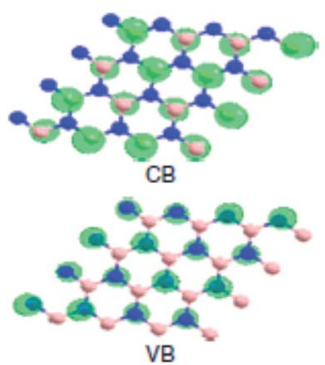

VB

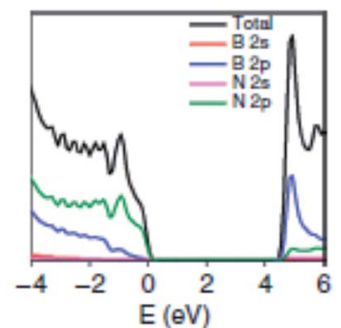

(b)

Fig. 7 The plane-wave DFT calculations of the electronic structure of $\mathrm{h}-\mathrm{BN}$ and $\mathrm{h}-\mathrm{BCN}$. The optimized structure of $\mathrm{B}_{16} \mathrm{~N}_{16}$ with the corresponding valence band (VB)/conduction band (CB) and the corresponding total and ion-decomposed electronic density of states (a and b). Reprinted with permission of ref. 215. Copyright 2015 Macmillan Publishers Limited. nanomaterials have attracted significant attention due to their unique $\mathrm{sp}^{2}$ hybrid carbon networks, exhibiting ultra-fast electron mobility at room temperature, conductivity, large theoretical surface area, high work function, etc. ${ }^{213-215}$ Huang et al. ${ }^{215}$ demonstrated a ternary structure of $\mathrm{B}-\mathrm{C}-\mathrm{N}$ nanosheets that has the functionality to catalyze $\mathrm{H}_{2}$ and $\mathrm{O}_{2}$ evolution from water as well as $\mathrm{CO}_{2}$ reduction under visible-light illumination. The plane-wave DFT calculations of the electronic structure of h-BN are shown in Fig. 5(a) and (b). ${ }^{215}$ As shown in Fig. 7(a) and (b), for a $\mathrm{B}_{11} \mathrm{C}_{12} \mathrm{~N}_{9}$ compound, the gap is significantly reduced from $4.56 \mathrm{eV}$ to $2.00 \mathrm{eV}$. The partial DOS, as shown in Fig. 7(b), signifies that the $\mathrm{VB}$ and $\mathrm{CB}$ edges of $\mathrm{B}_{11} \mathrm{C}_{12} \mathrm{~N}_{9}$ mainly comprise C $2 p$ orbitals, which is different from that of pure h-BN (Fig. 7(a)).

Metal chalcogenides have been found to be promising photocatalyst materials for photocatalytic $\mathrm{H}_{2}$ production due to their appropriate band gap width and band edge position. ${ }^{\mathbf{2 1 6}}$ In particular, CdS has been found to be an efficient semiconductor $\mathrm{H}_{2}$-production photocatalyst. ${ }^{217}$ However, some key issues such as the quick recombination of photogenerated charge carriers and photocorrosion under visible-light irradiation still exist and prohibit the wide application of CdS to a large extent. To solve these issues, forming $\mathrm{Zn}_{1-x} \mathrm{Cd}_{x} \mathrm{~S}$ solid solutions is a viable method because $\mathrm{ZnS}$ possesses the same coordination mode with $\mathrm{CdS},{ }^{\mathbf{2 1 8 - 2 2 0}}$ and the band gap width and band edge position of the $\mathrm{Zn}_{1-x} \mathrm{Cd}_{x} \mathrm{~S}$ solid solutions can be tuned by changing the molar ratio of $\mathrm{ZnS}$ and $\mathrm{CdS}^{.21,222}$ For example, Li et al. ${ }^{223}$ demonstrated the visible-light photocatalytic $\mathrm{H}_{2}$ production activity of $\mathrm{Zn}_{1-x} \mathrm{Cd}_{x} \mathrm{~S}$ solid solutions with different molar ratios of ZnS and CdS using both experimental and DFT methods. The authors found that for $\mathrm{Zn} / \mathrm{Cd}$ with a molar ratio equal to $1: 1$, the $\mathrm{Zn}_{0.5} \mathrm{Cd}_{0.5} \mathrm{~S}$ solid solution exhibits the highest $\mathrm{H}_{2}$-production rate of $7.42 \mathrm{mmol} \mathrm{h}^{-1} \mathrm{~g}^{-1}$, exceeding that of the pure CdS and $\mathrm{ZnS}$ samples by more than 24 and 54 times, respectively. The supercell models for bulk $\mathrm{ZnS}$ and CdS, the geometry of $\mathrm{Zn}_{0.5} \mathrm{Cd}_{0.5} \mathrm{~S}$, the band structures of the $\mathrm{Zn}_{1-x} \mathrm{Cd}_{x} \mathrm{~S}$ systems for various $\mathrm{Zn} / \mathrm{Cd}$ molar ratios and the conduction and valence band edge potentials of the samples $(x=0,0.1,0.3,0.5,0.7,0.9$, and 1.0) are shown in Fig. 8(a), (b) and (c), respectively. ${ }^{223}$ Fig. 8(d) shows that the band gap of the $\mathrm{Zn}_{1-x} \mathrm{Cd}_{x} \mathrm{~S}$ samples gradually becomes narrower from 1.921 to $1.141 \mathrm{eV}$ upon increasing the $\mathrm{Cd}$ content, which is well consistent with the experimental results.

Many studies have been conducted on the development of semiconducting material/graphene hybrid structures using either gas phase ${ }^{\mathbf{2 2 3 - 2 2 6}}$ or liquid phase techniques. ${ }^{\mathbf{1 8 5 , 1 8 6 , 1 9 1 , 2 2 7}}$ Hou et al. ${ }^{228}$ have developed a CdS QDs/graphene/ZnIn ${ }_{2} \mathrm{~S}_{4}$ system that exhibits highly efficient $\mathrm{H}_{2}$ production due to the high hydrothermal stability and efficient electron transfer. Graphene can also play a role as a co-catalyst and constitutes a synergistic effect with the other co-catalyst to improve the photocatalytic efficiency. ${ }^{229-231}$ Similarly, Zhu et al. ${ }^{230}$ demonstrated $\mathrm{ZnS}$ loaded with $0.25 \mathrm{wt} \%$ graphene and 2 atom $\% \mathrm{MoS}_{2}$ that yielded a high $\mathrm{H}_{2}$ production rate of $2258 \mu \mathrm{mol} \mathrm{h}^{-1}$, which is 2 times of that observed with $\mathrm{ZnS}$ only.

Consequently, there is a huge scarcity of theoretical investigations based on the DFT methods on nanophotocatalysts (both 


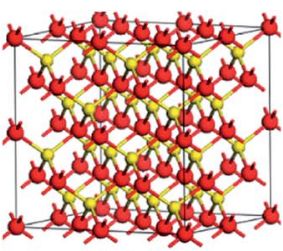

(a) $\mathrm{ZnS}$

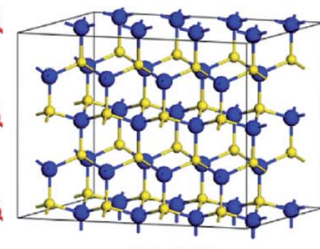

(b) $\mathrm{CdS}$

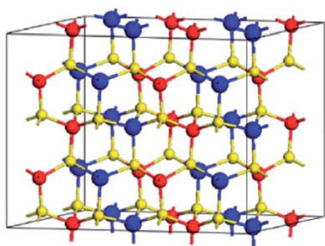

(c) $\mathrm{Zn}_{0.5} \mathrm{Cd} \mathrm{d}_{0.5} \mathrm{~S}$

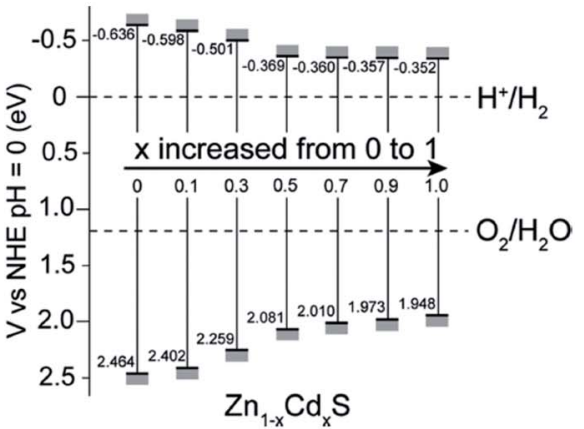

(d)

Fig. 8 The supercell models for bulk (a) ZnS (64 atoms) and (b) CdS (64 atoms). The red, yellow, and blue spheres represent the Zn, S, and Cd atoms, respectively. (c) The geometry model for $Z_{0.5} \mathrm{Cd}_{0.5} \mathrm{~S}$ and (d) conduction and valence band edge potentials of the $\mathrm{Zn}_{1-x} \mathrm{Cd} \mathrm{S}_{x}$ samples $(x=$ $0,0.1,0.3,0.5,0.7,0.9$, and 1.0). Reprinted with permission of ref. 223. Copyright 2013 American Chemical Society.

metal-oxide and non-metal oxide) and modified photocatalysts for photocatalytic $\mathrm{H}_{2}$ production via water splitting. In the case of metal-oxide photocatalysts, few studies were reported on pure $\mathrm{TiO}_{2}$ and modified $\mathrm{TiO}_{2}$, which were focused on the electronic structures of modified $\mathrm{TiO}_{2}$, signifying the gap reduction and efficient charge separation due to doping of $\mathrm{TiO}_{2}$ to enhance the photocatalytic $\mathrm{H}_{2}$ production. Moreover, very few studies have been reported for graphene and metal chalcogenides in the form of B-C-N ternary compounds and multicomponent heterostructures (metal oxide/graphene/metal chalcogenides) for efficient photocatalytic $\mathrm{H}_{2}$ production due to the synergistic effect of graphene and $\mathrm{MoS}_{2}$. There is a big opportunity for theoretical researchers to conduct DFT calculations on metal oxide and nonmetal oxide photocatalysts and their modified forms for highly efficient photocatalytic $\mathrm{H}_{2}$ production. Therefore, more DFT investigations should be devoted to either experimentally explore photocatalysts and modified photocatalysts or on the exploration of new photocatalytic materials for highly efficient $\mathrm{H}_{2}$ production to a large extent.

\section{Summary and perspectives}

Herein, we reviewed nanostructured photocatalysts (both transition metal oxides and non-metal oxides) and modified photocatalysts for highly efficient $\mathrm{H}_{2}$ production via water splitting under both UV and visible-light irradiation investigated via DFT techniques. However, the current lack of industrial applications of current semiconductor-based photocatalytic $\mathrm{H}_{2}$ production is mainly due to two reasons: the low photocatalytic efficiency and lack of extensive studies for successful industrial applications of photocatalytic $\mathrm{H}_{2}$ production experimentally as well as the lack of DFT studies to investigate the factors responsible for the enhancement of the efficiency of $\mathrm{H}_{2}$ production. The current $\mathrm{H}_{2}$ production yield is quite low, which is far from the targeted quantitative efficiency of $30 \%$ at $600 \mathrm{~nm}$ for practical applications. ${ }^{232}$ The critical light conversation efficiency for photocatalytic $\mathrm{H}_{2}$ production via water splitting is about $15 \% .{ }^{233}$ In this regard, the present research does not explore the highly efficient and cost-effective photocatalysts and modified photocatalysts for $\mathrm{H}_{2}$ production via water splitting. The reason is that the present metal oxide and non-metal oxide photocatalysts have wide band gaps, which do not absorb sufficient sunlight in the visible-light region. To reduce the band gaps towards visible-light absorption and photogenerated charge separation in photocatalysis, the photocatalysts have been modified using different techniques in different forms. However, the modified photocatalysts do not enhance the efficiency of $\mathrm{H}_{2}$ production from the decomposition of water under visible-light irradiation. Moreover, the fast charge recombination and fast back reactions are also drawbacks for the solar water splitting system. ${ }^{234-236}$ DFT investigations have reported the control of band gap and band edge positions via variations of the morphology, composition, crystallinity, and surface structure of photocatalysts for efficient $\mathrm{H}_{2}$ or $\mathrm{O}_{2}$ evolution from water splitting.

Consequently, more theoretical studies should be devoted towards the exploration of highly efficient, stable, eco-friendly and cost-effective photocatalysts, and modified photocatalysts via the continual addition of electron donors to overcome the key issues of current solar water splitting systems in the production of $\mathrm{H}_{2}$ to a larger extent.

\section{Acknowledgements}

This work was supported by the Korea Center for Artificial Photosynthesis (KCAP, 2009-0093880, 2009-0093886), Basic Science Research Program (No. 2012-017247), BK Plus Program and A3 Foresight Program, all funded by the Ministry of Science, ICT and Future Planning through the National Research Foundation (NRF) Korea.

\section{References}

1 J. A. Turner, Science, 2004, 305, 972. 
2 C. Liao, C. Huang and J. C. S. Wu, Catalysts, 2012, 2, 490.

3 S. C. Tsang, J. B. Claridge and M. L. H. Green, Catal. Today, 1995, 23, 3.

4 G. A. Olah and A. Molnar, Hydrocarbon chemistry, Wiley Interscience, 1995.

5 L. G. Thomas and A. K. Nelson, Int. J. Hydrogen Energy, 2010, 35, 900.

6 L. Barelli, G. Bidini, F. Gallorini and A. Ottaviano, Int. J. Hydrogen Energy, 2011, 36, 3206.

7 M. Ni, M. K. H. Leung and D. Y. C. Leung, Energy Convers. Manage., 2007, 48, 1525.

8 I. Dincer, Int. J. Energy Res., 2007, 31, 29.

9 A. Saeed, M. Ali and S. Mahrokh, Int. J. Hydrogen Energy, 2010, 35, 9283.

10 T. A. H. Ratlamwala, A. L. El-Sinawi, M. A. Gadalla and A. Aidan, Int. J. Energy Res., 2012, 36, 1121.

11 A. Kudo, Pure Appl. Chem., 2007, 79, 1917.

12 A. Fujishima and K. Honda, Nature, 1972, 238, 37.

13 Y. Li and J. Z. Zhang, Laser Photonics Rev., 2010, 4, 517.

14 Z. Chen, T. F. Jaramillo, T. G. Deutsch, A. KleimanShwarsctein, A. J. Forman, N. Gaillard, R. Garland, K. Takanabe, C. Heske, M. Sunkara, E. W. McFarland, K. Domen, E. L. Miller, J. A. Turner and H. N. Dinh, J. Mater. Res. Technol., 2010, 25, 3.

15 L. J. Minggu, W. R. W. Daud and M. B. Kassim, Int. J. Hydrogen Energy, 2010, 35, 5233.

16 R. van de Krol and Y. S. Liang, J. Mater. Chem., 2008, 18, 2311.

17 B. D. Alexander, P. J. Kulesza, I. Rutkowska, R. Solarska and J. Augustynski, J. Mater. Chem., 2008, 18, 2298.

18 K. J. Rajeshwar, J. Appl. Electrochem., 2007, 37, 765.

19 V. M. Aroutiounian, V. M. Arakelyan and G. E. Shahnazaryan, Sol. Energy, 2005, 78, 581.

20 A. Steinfeld, Int. J. Hydrogen Energy, 2002, 27, 611.

21 I. Akkerman, M. Janssen, J. Rocha and R. H. Wijffels, Int. J. Hydrogen Energy, 2002, 27, 1195.

22 D. Das and T. N. Veziroglu, Int. J. Hydrogen Energy, 2008, 33, 6046.

23 Y. F. Guan, M. C. Deng, X. J. Yu and W. Zhang, Biochem. Eng. J., 2004, 1, 69.

24 J. S. Jang, H. G. Kim, U. A. Joshi, J. W. Jang and J. S. Lee, Int. J. Hydrogen Energy, 2008, 33, 5975.

25 P. J. Sebastian, R. Castaneda, L. Ixtlilco, R. Mejia, J. Pantoja and A. Olea, Proc. SPIE, 2008, 7044, 704405.

26 L. A. Silva, S. Y. Ryu, J. Choi, W. Choi and M. R. Hoffmann, J. Phys. Chem. C, 2008, 112, 12069.

27 M. Ni, M. K. H. Leung, D. Y. C. Leung and K. Sumathy, Renewable Sustainable Energy Rev., 2007, 11, 401.

28 X. Chen, T. Yu, X. Fan, H. Zhang, Z. Li, J. Ye and Z. Zou, Appl. Surf. Sci., 2007, 253, 8500.

29 Y. Takahara, J. Konde, N. T. Takata, D. Lu and K. Domen, Chem. Mater., 2001, 13, 1194.

30 J. Y. Kim, J. W. Jang, D. H. Youn, G. Magesh and J. S. Lee, Adv. Energy Mater., 2014, 4, 1400476.

31 K. Sivula, F. Le Formal and M. Gratzel, ChemSusChem, 2011, 4, 432 .

32 A. I. Hochbaum and P. Yang, Chem. Rev., 2010, 110, 527.
33 Y. J. Lin, G. B. Yaun, R. Liu, S. Zhou, S. W. Sheehan and D. W. Wang, Chem. Phys. Lett., 2011, 507, 209.

34 G. Hitoki, T. Takata, J. N. Kondo, M. Hara, H. Kobayashi and K. Domen, Chem. Commun., 2002, 1698.

35 A. Kudo, K. Ueda, H. Kato and I. Mikami, Catal. Lett., 1998, 53, 229.

36 A. Kudo, K. Omori and H. Kato, J. Am. Chem. Soc., 1999, 121, 11459.

37 X. Liu, F. Wang and Q. Wang, Phys. Chem. Chem. Phys., 2012, 14, 7894.

38 E. Baniasadi, I. Diner and G. F. Naterer, Chem. Eng. Sci., 2012, 84, 638.

39 N. L. Wu and M. S. Lee, Int. J. Hydrogen Energy, 2004, 29, 1601.

40 S. Sakthivel, M. V. Shankar, M. Palanichamy, B. Arabindoo, D. W. Bahnemann and V. Murugesan, Water Res., 2004, 38, 3001.

41 S. Kim and W. Choi, J. Phys. Chem. B, 2002, 106, 13311.

42 S. Jin and F. Shiraishi, Chem. Eng. J., 2004, 97, 203.

43 V. Subramanian, E. E. Wolf and P. Kamat, J. Am. Chem. Soc., 2004, 126, 4943.

44 I. H. Tseng, J. C. S. Wu and H. Y. Chou, J. Catal., 2004, 221, 432.

45 S. X. Liu, Z. P. Qu, X. W. Han and C. L. Sun, Catal. Today, 2004, 93-95, 877.

46 P. V. Kamat, M. Flumiani and A. Dawson, Colloids Surf., A, 2002, 202, 269.

47 E. S. Bardos, H. Czili and A. Horvath, J. Photochem. Photobiol., A, 2003, 154, 195.

48 K. A. Johnson and N. W. Asheroft, Phys. Rev. B: Condens. Matter Mater. Phys., 1998, 58, 15548.

49 W. Kohn and L. J. Sham, Phys. Rev., 1965, 140, A1133.

50 (a) J. P. Perdew and W. Yue, Phys. Rev. B: Condens. Matter Mater. Phys., 1986, 33, 8800; (b) J. P. Perdew, K. Burke and M. Ernzerhof, Phys. Rev. Lett., 1996, 77, 3865.

51 J. P. Perdew, M. Ernzerhof and K. Burke, J. Chem. Phys., 1996, 105, 9982.

52 I. A. Vladimir, F. Aryasetiawan and A. I. Lichtenstein, J. Phys.: Condens. Matter, 1997, 9, 767.

53 (a) F. Aryastiawan and O. Gunnarsson, Rep. Prog. Phys., 1998, 61, 237; (b) C. Franchini, R. Kovaik, M. Marsman, S. S. Murthy, J. He, C. Ederer and G. Kresse, J. Phys.: Condens. Matter, 2012, 24, 235; (c) J. Y. Gou, J. W. Benett, H. Takenaka and A. M. Rappe, Phys. Rev. B: Condens. Matter Mater. Phys., 2011, 83, 205115.

54 M. Law, L. E. Greene, J. C. Johnson, R. Saykally and P. D. Yang, Nat. Mater., 2005, 4, 455.

55 X. Chen, S. Shen, L. S. Guo and S. Mao, Chem. Rev., 2010, 110, 6503.

56 Y. Moriya, T. Takatab and K. Domen, Coord. Chem. Rev., 2013, 257, 1957.

57 A. J. Bard and M. A. Fox, Acc. Chem. Res., 1995, 28, 141.

58 O. Akhavan and R. Azimirad, Appl. Catal., A, 2009, 369, 62.

59 X. Li, Y. Hou, Q. Zhao, W. Teng, X. Hu and G. Chen, Chemosphere, 2011, 82, 581.

60 E. Zintl and L. Varino, Process for the manufacture of pure bismuth vanadate, German Patent, 422947, 1925. 
61 J. Tang, Z. Zou and J. Ye, Angew. Chem., Int. Ed., 2004, 43, 4463.

62 J. Tang, Z. Zou and J. Ye, Chem. Mater., 2004, 16, 1644.

63 K. Kaur and C. V. Singh, Energy Procedia, 2012, 29, 291.

64 A. Reynal, J. Willkomm, N. M. Muresan, F. Lakadamyali, M. Planells, E. Reisner and J. R. Durrant, Chem. Commun., 2014, 50, 12768.

65 G. Geneste, E. Bousquet, J. Junquera and P. Ghosez, Appl. Phys. Lett., 2006, 88, 112906.

66 G. Pilania, S. P. Alpay and R. Ramprasad, Phys. Rev. B: Condens. Matter Mater. Phys., 2009, 80, 014113.

67 T. Shimada, S. Tomoda and T. Kitamura, Phys. Rev. B: Condens. Matter Mater. Phys., 2009, 79, 024102.

68 G. Pilania and R. Ramprasad, Phys. Rev. B: Condens. Matter Mater. Phys., 2010, 82, 155442.

69 G. Pilania and R. Ramprasad, J. Mater. Sci., 2012, 47, 7580.

70 Q. Fu, T. He, J. L. Li and G. W. Yang, J. Appl. Phys., 2012, 111, 124306.

71 Q. Fu, T. He, J. L. Li and G. W. Yang, J. Appl. Phys., 2012, 112, 104322.

72 Q. Fu, T. He, J. L. Li and G. W. Yang, J. Appl. Phys., 2013, 113, 104303.

73 A. V. Bandura, R. A. Evarestov and Y. F. Zukovskii, RSC Adv., 2015, 5, 24115.

74 Y. F. Zhukovskii, S. Piskunov, J. Begens, J. Kazerovskis and O. Lisovski, Phys. Status Solidi B, 2013, 250, 793.

75 N. Daude, C. Gout and C. Jouanin, Phys. Rev. B: Solid State, 1977, 15, 3229.

76 K. M. Reddy, S. V. Manorama and A. R. Reddy, Mater. Chem. Phys., 2003, 78, 239.

77 T. Morikawa, R. Asahi, T. Ohwaki, K. Aoki and Y. Taga, Jpn. J. Appl. Phys., Part 2, 2001, 40, 561.

78 A. Sclafani and J. M. Herrmann, J. Phys. Chem., 1996, 100, 13655.

79 H. Kominami, Y. Ishii, M. Kohno, S. Konishi, Y. Kera and B. Ohtani, Catal. Lett., 2003, 91, 41.

80 B. Ohtani, J. Handa, S. Nishimoto and T. Kagiya, Chem. Phys. Lett., 1985, 120, 292.

81 H. Hu, H. L. Tsai and C. L. Huang, J. Eur. Ceram. Soc., 2003, 23, 691.

82 H. Wang and J. P. Lewis, J. Phys.: Condens. Matter, 2006, 18, 421.

83 D. Hanaor, M. Michelazzi, J. Chenu, C. Leonelli and C. C. Sorrell, J. Eur. Ceram. Soc., 2011, 31, 2877.

84 G. Liu, L. Wang, H. G. Yang, H. M. Cheng and G. Q. M. Lu, J. Mater. Chem., 2009, 20, 831.

85 A. Kudo and Y. Miseki, Chem. Soc. Rev., 2008, 38, 253.

86 A. Burns, W. Li, C. Baker and S. I. Shah, Mater. Res. Soc. Symp. Proc., 2002, 703, 5.2.1.

87 M. Batzill, E. H. Morales and U. Diebold, Phys. Rev. Lett., 2006, 96, 26103.

88 B. Xin, Z. Ren, P. Wang, L. Jing, H. Fu and J. Liu, Appl. Surf. Sci., 2007, 253, 4390.

89 B. Sun, A. V. Vorontsov and P. G. Smirniotis, Langmuir, 2003, 19, 3151.

90 K. Nagaveni, M. S. Hegde, N. Ravishankar, G. N. Subbanna and G. Madrass, Langmuir, 2004, 20, 2900.
91 N. Serpone, J. Phys. Chem. B, 2006, 110, 24287.

92 T. Umebayashi, T. Yamaki, H. Itoh and K. Asai, Appl. Phys. Lett., 2002, 81, 454.

93 K. V. Baiju, C. P. Sibu, K. Rajesh, P. K. Pillai, P. Mukundan, K. G. K. Warrier and W. Wunderlich, Mater. Chem. Phys., 2005, 90, 123.

94 D. Kim, T. Kim and K. Hong, Mater. Res. Bull., 1999, 34, 771.

95 J. Kim, K. C. Song, S. Foncillas and S. Pratsinis, J. Eur. Ceram. Soc., 2001, 21, 2863.

96 D. J. Reidy, J. D. Holmes, C. Nagle and M. A. Morris, J. Mater. Chem., 2005, 3494.

97 S. D. Sharma, D. Singh, K. Saini, C. Kant, V. Sharma, S. C. Jain and C. P. Sharma, Appl. Catal., A, 2006, 314, 40.

98 D. Hanaor and C. C. Sorrell, J. Mater. Sci., 2011, 46, 855.

99 K. J. D. Mackenzie, Trans. J. Br. Ceram. Soc., 1975, 74, 77.

100 D. A. H. Hanaor, M. H. N. Asadi, S. Li, A. Yu and C. S. Sorrell, Comput. Mech., 2012, 50, 185.

101 Y. Takashi and Y. Mastuoka, J. Mater. Sci., 1988, 23, 2259.

102 J. C. Yu, J. Yu, W. Ho, Z. Jiang and L. Zhang, Chem. Mater., 2002, 14, 3808.

103 C. Di Valentin, G. Pacchioni, H. Onishi and H. Kudo, Chem. Phys. Lett., 2009, 469, 166.

104 C. Di Valentin, E. Finazzi, G. Pacchioni, A. Selloni, S. Livarghi, M. C. Paganini and E. Giamello, Chem. Phys., 2007, 339, 44.

105 J. G. Yu, Q. J. Xiang, M. H. Zhou and X. Y. Zhou, Appl. Catal., $B, 2009,90,595$.

106 R. Long and N. J. English, J. Phys. Chem. C, 2010, 114, 11984.

107 J. W. Zheng, A. Bhattcahrayya, P. Wu, Z. Chen, J. Highfield, Z. L. Dong and R. Xu, J. Phys. Chem. C, 2010, 114, 7063.

108 X. L. Nie, S. P. Zhou, G. Maeng and K. Sohlberg, Int. J. Photoenergy, 2009, 294042.

109 Y. Cui, H. H. Du and L. S. Wen, J. Mater. Sci. Technol., 2008, 24, 675 .

110 H. W. Peng, J. B. Li, S. S. Li and J. B. Xia, J. Phys.: Condens. Matter, 2008, 20, 125207.

111 A. Iwaszuk and M. Nolan, J. Phys. Chem. C, 2011, 115, 12995.

112 M. Liu, L. Piao, L. Zhao, S. Ju, Z. Yan, T. He, C. Zhou and W. Wang, Chem. Commun., 2010, 46, 1664.

113 W. Yang, J. Li, Y. Wang, F. Zhu, W. Shi, F. Wan and D. Xu, Chem. Commun., 2011, 47, 1809.

114 L. Gu, J. Wang, H. Cheng, Y. Du and X. Han, Chem. Commun., 2012, 48, 6978.

115 J. Qiu, S. Zhang and H. Zhao, J. Hazard. Mater., 2012, 211212, 381.

116 C. Aprile, A. Corma and H. Garcia, Phys. Chem. Chem. Phys., 2008, 10, 769.

117 C. X. Kronawitter, L. Vayssieres, S. Shen, L. Guo, D. A. Wheeler, J. Z. Zhang, B. R. Antoun and S. S. Mao, Energy Environ. Sci., 2011, 4, 3889.

118 F. A. Frame, T. K. Townsend, R. L. Chamousis, E. M. Sabio, Th. Dittrich, N. D. Browning and F. E. Osterloh, J. Am. Chem. Soc., 2011, 133, 7264.

119 M. Law, L. E. Greene, J. C. Johnson, R. Saykally and P. Yang, Nat. Mater., 2005, 4, 455. 
120 Y. Cao, T. He, Y. Chen and Y. Cao, J. Phys. Chem. C, 2010, 114, 3627.

121 L. Kong, Z. Jiang, T. Xiao, L. Lu, M. Jones and P. P. Edwards, Chem. Commun., 2011, 47, 5512.

122 H. Cheng, B. Huang, Y. Dai, X. Qin and X. Zhang, Langmuir, 2010, 26, 6618.

123 S. Hong, S. Lee, J. Jang and J. Lee, Energy Environ. Sci., 2011, 4, 1781.

124 T. Cao, Y. Li, C. Wang, Z. Zhang, M. Zhang, C. Shao and Y. Liu, J. Mater. Chem., 2011, 21, 6922.

125 V. Bharat, R. Boppana and R. F. Lobo, ACS Catal., 2011, 1, 923.

126 J. Libera, J. Elam, N. Sather, T. Rajh and N. M. Dimitrijevic, Chem. Mater., 2010, 22, 409.

127 H. Tada, Q. Jin, H. Nishijima, H. Yamamoto, M. Fujishima, S.-I. Okuoka, T. Hattori, Y. Sumida and H. Kobayashi, Angew. Chem., Int. Ed., 2011, 50, 3501.

128 Q. Jin, M. Fujishima and H. Tada, J. Phys. Chem. C, 2011, 115, 6478.

129 Q. Jin, Y. Ikeda, M. Fujishima and H. Tada, Chem. Commun., 2011, 47, 8814.

130 M. Fujishima, Q. Jin, H. Yamamoto, H. Tada and M. Nolan, Phys. Chem. Chem. Phys., 2012, 14, 705.

131 Q. Jin, M. Fujishima, M. Nolan, A. Iwaszuk and H. Tada, J. Phys. Chem. C, 2012, 116, 12621.

132 M. Nolan, Phys. Chem. Chem. Phys., 2011, 13, 18194.

133 A. Iwaszuk and M. Nolan, Phys. Chem. Chem. Phys., 2011, 13, 4963.

134 M. Nolan, ACS Appl. Mater. Interfaces, 2012, 4, 5863.

135 E. P. Reddy, L. Davydov and P. Smirniotis, Appl. Catal., B, 2003, 42, 1.

136 M. Hirano, K. Ota and H. Iwata, Chem. Mater., 2004, 16, 3725.

137 W. Wang, C. G. Silva and J. L. Faria, Appl. Catal., B, 2007, 70, 470.

138 T. Torimoto, Y. Okawa, N. Takeda and H. Yoneyama, J. Photochem. Photobiol., A, 1997, 103, 153.

139 C. H. Ao and S. C. Lee, Appl. Catal., B, 2003, 44, 191.

140 J. Arana, J. M. Doña-Rodríguez, E. Tello Rendón, C. Garriga, I. Cabo, O. González-Díaz, J. A. Herrera-Melián, J. PérezPeña, G. Colón and J. A. Navío, Appl. Catal., B, 2003, 44, 161.

141 P. Fu, Y. Luan and X. Dai, J. Mol. Catal. A: Chem., 2004, 221, 81.

142 X. Zhang, M. Zhou and L. Lei, Carbon, 2005, 43, 1700.

143 A. Jitianu, T. Cacciaguerra, R. Benoit, S. Delpeux, F. Béguin and S. Bonnamy, Carbon, 2004, 42, 1147.

144 H. Huang, W. K. Zhang, X. P. Gan, C. Wang and L. Zhang, Mater. Lett., 2007, 61, 296.

145 I. Moriguchi, R. Hidaka, H. Yamada, T. Kudo, H. Murakami and N. Nakashima, Adv. Mater., 2006, 18, 69.

146 S. R. Jang, R. Vittal and K.-J. Kim, Langmuir, 2004, 20, 9807. 147 Y. Yao, G. Li, S. Ciston, R. M. Lueptow and K. A. Gray, Environ. Sci. Technol., 2008, 42, 4952.

148 B. Liu and H. C. Zeng, Chem. Mater., 2008, 20, 2711.

149 B. Gao, G. Z. Chen and P. G. Li, Appl. Catal., B, 2009, 89, 503.

150 K. Woan, G. Pyrgiotakis and W. Sigmund, Adv. Mater., 2009, 21, 2233.
151 D. Wang, D. Choi, J. Li, Z. Yang, Z. Nie, R. Kou, D. Hu, C. Wang, L. V. Saraf and J. Zhang, ACS Nano, 2009, 3, 907.

152 H. Zhang, X. Lv, Y. Li, Y. Wang and J. Li, ACS Nano, 2009, 4, 380.

153 Y.-B. Tang, et al., ACS Nano, 2010, 4, 3482.

154 M. J. McAllister, J. L. Li, D. H. Adamson, H. C. Schniepp, A. A. Abdala, J. Liu, M. Herrera-Alonso, D. L. Milius, R. Car and R. K. Prud'homme, Chem. Mater., 2007, 19, 4396.

155 N. Farhangi, Y. Medina-Gonzalez, R. R. Chowdhury and P. A. Charpentier, Nanotechnology, 2012, 23, 294005.

156 N. Farhangi, R. R. Chowdhury, Y. Medina-Gonzalez, M. B. Ray and P. A. Charpentier, Appl. Catal., B, 2011, 110, 25.

157 B. Das, B. Choudhury, A. Gomathi, A. K. Manna, S. K. Pati and C. N. R. Rao, ChemPhysChem, 2011, $12,937$.

158 S. K. Deb, Sol. Energy Mater. Sol. Cells, 2008, 92, 245.

159 S. K. Deb, Appl. Opt., 1969, 3, 192.

160 S. K. Deb, Philos. Mag., 1973, 27, 801.

161 J. M. Berek and J. Sienko, J. Solid State Chem., 1970, 2, 109.

162 M. A. Butler, R. D. Nasby and R. K. Quinn, Solid State Commun., 1976, 19, 1011.

163 D. E. Scaife, Sol. Energy, 1980, 25, 41.

164 A. J. Nozik, Annu. Rev. Phys. Chem., 1978, 29, 189.

165 G. R. Bamwenda and H. Arakawa, Appl. Catal., A, 2001, 210, 181.

166 L. Weinhardt, M. Blum, M. Bär, C. Heske, B. Cole, B. Marsen and E. L. Miller, J. Phys. Chem. C, 2008, 112, 3078.

167 X. C. Song, E. Yang, G. Liu, Y. Zhang, Z. S. Liu, H. F. Chen and Y. Wang, J. Nanopart. Res., 2010, 12, 2813.

168 L. Zhou, J. Zhu, M. Yu, X. Huang, Z. Li, Y. Wang and C. Yu, J. Phys. Chem. C, 2010, 114, 20947.

169 A. Hameed, M. A. Gondal and Z. H. Yamani, Catal. Commun., 2004, 5, 715.

170 M. Radecka, P. Sobas, M. Wierzbicka and M. Rekas, Phys. B, 2005, 364, 85.

171 X. F. Cheng, W. H. Leng, D. P. Liu, J. Q. Zhang and C. N. Cao, Chemosphere, 2007, 68, 1976.

172 H. Liu, T. Peng, D. Ke, Z. Peng and C. Yan, Mater. Chem. Phys., 2007, 104, 377.

173 B. Yang and V. Luca, Chem. Commun., 2008, 4454-4456.

174 A. Enesca, A. Duta and J. Schoonman, Phys. Status Solidi A, 2008, 205, 2038.

175 K. M. Karuppasamy and A. Subrahmanyam, J. Phys. D: Appl. Phys., 2008, 41, 035302.

176 P. Maruthamuthu, M. Ashokkumar, K. Gurunathan, E. Subramanian and M. V. C. Sastri, Int. J. Hydrogen Energy, 1989, 14, 525.

177 W. Erbs, J. Desilvestro, E. Borgarello and M. Gräzel, J. Phys. Chem., 1984, 88, 4001.

178 X. Chang, S. Sun, Y. Zhou, L. Dong and Y. Yin, Nanotechnology, 2011, 22, 265603.

179 F. Wang, C. Di Valentin and G. Pacchioni, J. Phys. Chem. C, 2012, 116, 8901.

180 C. Zhou, G. Chen, Y. X. Li, H. J. Zhang and J. Pei, Int. J. Hydrogen Energy, 2009, 34, 2113.

181 R. Shi, J. Lin, Y. J. Wang, J. Xu and Y. F. Zhu, J. Phys. Chem. $C, 2010,114,6472$. 
182 D. W. Hwang, H. G. Kim, J. S. Lee, J. Kim, W. Li and S. H. Oh, J. Phys. Chem. B, 2005, 109, 2093.

183 C. Diaz-Guerra, P. Umek, A. Gloter and J. Piqueras, J. Phys. Chem. C, 2010, 114, 8192.

184 X. Liu, Y. Meng and X. Wang, IPCBEE, 2012, 38, 115.

185 J. M. Lee, Y. B. Pyun, J. Yi, J. W. Choung and W. I. Park, J. Phys. Chem. C, 2009, 113, 19134.

186 W. T. Song, J. Xie, S. Y. Liu, Y. X. Zheng, G. S. Cao, T. J. Zhu, et al., Int. J. Electrochem. Sci., 2012, 7, 2164.

187 G. Ambrozic, S. D. Škapin, M. Zigon and Z. C. Orel, J. Colloid Interface Sci., 2010, 346, 317.

188 D. Fan, R. Zhang, X. Wang, S. Huang and H. Peng, Phys. Status Solidi A, 2012, 209, 335.

189 S. Music, A. Šarić and S. Popović, Ceram. Int., 2010, 36, 1117.

190 T. Singh, D. K. Pandya and R. Singh, Thin Solid Films, 2012, 520, 4646.

191 N. F. Ahmad, N. L. Rusli, M. R. Mahmood, K. Yasui and A. M. Hashim, Nanoscale Res. Lett., 2014, 9, 83.

192 X. Pengtao, T. Qing and Z. Zhen, Nanotechnology, 2013, $24,1$.

193 Q. J. Xiang, J. G. Yu and M. Jaroniec, J. Am. Chem. Soc., 2012, 134, 6575.

194 S. Kanda, T. Akita, M. Fujishima and H. Tada, J. Colloid Interface Sci., 2011, 354, 607.

195 A. Wu, L. Jing, J. Wang, Y. Qu, Y. Xie, B. Jiang, C. Tian and H. Fu, Sci. Rep., 2015, 5, 88581.

196 E. Grabowska, et al., J. Phys. Chem. C, 2013, 117, 1955.

197 X. Wang, et al., Nat. Mater., 2009, 8, 76.

198 X. Lang, X. Chen and J. Zhao, Chem. Soc. Rev., 2014, 43, 473.

199 G. Liu, L. C. Yin, P. Niu, W. Jiao and H. M. Cheng, Angew. Chem., Int. Ed., 2013, 52, 6242.

200 G. Liu, P. Niu, L. Yin and H. M. Cheng, J. Am. Chem. Soc., 2012, 134, 9070.

201 F. Wang, et al., Appl. Catal., B, 2012, 111-112, 409.

202 X. Wang, et al., Nat. Mater., 2009, 8, 76.

203 J. Liu, et al., Angew. Chem., Int. Ed., 2013, 52, 3241.

204 K. S. Novoselov, et al., Science, 2004, 306, 666.

205 N. G. Chopra, et al., Science, 1995, 269, 966.

206 K. Watanabe, T. Taniguchi and H. Kanda, Nat. Mater., 2004, 3, 404.

207 L. Song, et al., Adv. Mater., 2012, 24, 4878.

208 L. Ci, et al., Nat. Mater., 2010, 9, 430.

209 J. Lu, et al., Nat. Commun., 2013, 4, 2681.

210 X. Li, J. Zhao and J. Yang, Sci. Rep., 2013, 3, 1858.

211 L. Song, et al., Nano Lett., 2010, 10, 3209.

212 K. S. Novoselov, A. K. Geim, S. V. Morozov, D. Jiang, Y. Zhang, S. V. Dubonos, I. V. Grigorieva and A. A. Firsov, Science, 2004, 306, 666.

213 X. An and J. C. Yu, RSC Adv., 2011, 1, 1426.

214 H. Tang, C. M. Hessel, J. Wang, N. Yang, R. Yu, H. Zhao and D. Wang, Chem. Soc. Rev., 2014, 43, 4281.
215 C. Huang, C. Chen, M. Zhang, L. Lin, X. Ye, S. Lin, M. Antonietti and X. Wang, Nat. Commun., 2015, 6, 76981. 216 (a) S. Kanda, T. Akita, M. Fujishima and H. Tada, J. Colloid Interface Sci., 2011, 354, 607; (b) J. Zhang, J. G. Yu, Y. M. Zhang, Q. Li and J. R. Gong, Nano Lett., 2011, 11, 4774; (c) J. Zhang, S. W. Liu, J. G. Yu and M. Jaroniec, J. Mater. Chem., 2011, 21, 14655; (d) J. Zhang, J. G. Yu, M. Jaroniec and J. R. Gong, Nano Lett., 2012, 12, 4584.

217 (a) M. Matsumura, S. Furukawa, Y. Saho and H. Tsubomura, J. Phys. Chem., 1985, 89, 1327; (b) J. G. Yu, Y. F. Yu and B. Cheng, RSC Adv., 2012, 2, 11829; (c) Q. J. Xiang, B. Cheng and J. G. Yu, Appl. Catal., B, 2013, 138-139, 299.

218 J. G. Yu, J. Zhang and M. Jaroniec, Green Chem., 2010, 12, 1611.

219 X. X. Yu, J. G. Yu, B. Cheng and B. B. Huang, Chem.-Eur. J., 2009, 15, 6731.

220 L. Wang, W. Z. Wang, M. Shang, W. Z. Yin, S. M. Sun and L. Zhang, Int. J. Hydrogen Energy, 2010, 35, 19.

221 C. Wu, J. Zheng, C. L. Zacherl, P. Wu, Z. K. Liu and R. Xu, J. Phys. Chem. C, 2011, 115, 19741.

222 C. J. Xing, Y. J. Zhang, W. Yan and L. Guo, Int. J. Hydrogen Energy, 2006, 31, 2018.

223 Q. Li, H. Meng, P. Zhou, Y. Zheng, J. Wang, J. Yu and J. Gong, ACS Catal., 2013, 3, 882.

224 Q. Xiang, J. Yu and M. Jaroniec, Chem. Soc. Rev., 2012, 41, 782. 225 N. S. A. Aziz, T. Nishiyama, N. I. Rusli, M. R. Mahmood, K. Yasui and A. M. Hashim, Nanoscale Res. Lett., 2014, 9, 337.

226 N. S. A. Aziz, M. R. Mahmood, K. Yasui and A. M. Hashim, Nanoscale Res. Lett., 2014, 9, 95.

227 M. Hilder, O. Winther-Jensen, B. Winther-Jensen and D. R. MacFarlane, Phys. Chem. Chem. Phys., 2012, 14, 14034.

228 J. Hou, C. Yang, H. Cheng, Z. Wang, S. Jiao and H. Zhu, Phys. Chem. Chem. Phys., 2013, 15, 15660.

229 (a) J. M. Lee, Y. B. Pyun, J. Yi, J. W. Choung and W. I. Park, J. Phys. Chem. C, 2009, 113, 19134; (b) S. Zhuang, X. Xu, B. Feng, J. Hu, Y. Pang, G. Zhou, L. Tong and Y. Zhou, ACS Appl. Mater. Interfaces, 2014, 6, 613.

230 B. L. Zhu, B. Z. Lin, Y. Zhou, P. Sun, Q. R. Yao, Y. L. Chen and B. F. Gao, J. Mater. Chem. A, 2014, 2, 3819.

231 K. Maeda and K. Domen, J. Phys. Chem. C, 2007, 111, 7851. 232 R. M. Navarro, M. C. Sanchez-Sanchez, M. C. AlvarezGalvan, F. del Valle and J. L. G. Fierro, Energy Environ. Sci., 2009, 2, 35.

233 X. Feng, W. Mao and W. Yan, Int. J. Hydrogen Energy, 2008, 33, 3644.

234 K. Domen, Y. Ebina, T. Sekine, A. Tanaka, J. Kondo and C. Hirose, Catal. Today, 1993, 16, 479.

235 Z. L. Jin and X. G. Lu, Energy Fuels, 2005, 19, 1126.

236 S. M. Ji, H. Jun, J. S. Jang, H. C. Son, P. H. Borse and J. S. Lee, J. Photochem. Photobiol., A, 2007, 189, 141. 